\title{
¿Una amistad desinteresada? Porfirio Díaz, Ezequiel Montes y su Discurso del 6 de julio de 1877
}

\section{A selfless friendship? Porfirio Díaz, Ezequiel Montes and his Speech of July 6, 1877}

\section{César Omar Tenorio Nava *}

* Facultad de Filosofía y Letras de la Universidad Nacional Autónoma de México, Ciudad de México. Es coautor del libro Historia de México 2, publicado por editorial Esfinge. Ha presentado las ponencias "Sobre el concepto de ciudadano y la difusión de los valores cívicos en el periódico queretano 'Los Amigos del Pueblo'”. 1832, “De gérmenes y bacterias. Políticas de sanidad en la Ciudad de México. El caso de las viruelas de 1779" y "La formación de un letrado. Biografía intelectual de Ezequiel Montes Ledesma. 1838-1854". Correo electrónico: omarguazu@hotmail.com

https://orcid.org/0000-0002-6046-6158

Historial editorial

Recibido: 20-junio-2020

Aceptado: 23-noviembre-2020

Publicado: 29-enero-2021

ISSN-e: 2594-2956 
¿Una amistad desinteresada? Porfirio Díaz, Ezequiel Montes y su Discurso del 6 de julio de 1877

\section{Resumen}

En este artículo analizamos el Discurso del 6 de julio de I877 escrito por Ezequiel Montes Ledesma, uno de los liberales menos estudiados del siglo XIX, pese a sus importantes contribuciones a la implementación del proyecto reformista que, entre otras cosas, permitió la consolidación del Estado laico mexicano. Sin embargo, su actividad política ha sido relegada a un segundo plano por la historiografía tradicional y sus obras aún no han despertado el interés de los investigadores. Precisamente, entre su numerosa producción destaca este discurso que presentó ante el pleno de la Suprema Corte de Justicia y con el cual no solamente obtuvo una resolución favorable para la solicitud de amparo de Faustino Goribar sino que, además, sentó las bases para la justificación del régimen tuxtepecano que recién había ascendido al poder. Por esta razón, el objetivo central de este trabajo consiste en examinar dicho alegato, utilizando para ello los principios de la hermenéutica jurídica y, de este modo, comprender los recursos retóricos utilizados por Montes. Finalmente, la hipótesis que sustenta nuestro trabajo consiste en demostrar que, en sus inicios, el movimiento tuxtepecano que llevó a Porfirio Díaz a la presidencia fue interpretado por Ezequiel como el último intento para lograr que se respetara a cabalidad el texto original de la Constitución Federal de 1857 , pues esta había sido modificada en diferentes ocasiones por las administraciones anteriores, las cuales no dudaron en recurrir al uso de las facultades extraordinarias.

Palabras Clave: Suprema Corte de Justicia, Revolución de Tuxtepec, amparo, constitución, facultades extraordinarias.

\section{A selfless friendship? Porfirio Díaz, Ezequiel} Montes and his Speech of July 6, 1877

\section{Abstract}

This article analyzes a speech delivered on July 6, I877 by Ezequiel Montes Ledesma. The author has been one of the least studied liberals of 19th century Mexican history, in spite of his significant contributions to the Liberal Reform movement that, among other things, allowed for the consolidation of Mexican secularism. The role of MontesLedesma's political activism has been overlooked by traditional historiography and his works have not received considerable attention by researchers. The aforementioned lecture stands out among his numerous publications since the speech's request, delivered during a plenary session of the Supreme Court of Justice not only received a favorable resolution for the "amparo" or legal protection request for Faustino Goribar but also laid the foundations for the justification of the "regimen tuxtepecano" that was seen as an emerging power. Thus, the main objective and hypothesis of the present work are respectively: to examine the forenamed speech using the principles of legal hermeneutics to try to understand the rhetorical resources used by Montes-Ledesma and to demonstrate that, in its beginnings, the "Tuxtepecano movement" that led Porfirio Díaz to the presidency was interpreted by Ezequiel as the last attempt to ensure that the original text of the Federal Constitution of I857 was fully respected, as it had been modified on different occasions by previous administrations, which did not hesitate to resort to the use of extraordinary powers.

Keywords: Supreme Court of Justice, Tuxtepec Revolution, legal protection, Constitution, extraordinary powers. 
¿Une amitié distinguée? Porfirio Díaz, Ezequiel Mones et son discours du 6 juillet I877

\section{Résumé:}

Dans cet article, nous analysons le Discours du 6 juillet $\mathrm{I} 877$ écrit par Ezequiel Montes Ledesma, l'un des libéraux les moins étudiés du XIXe siècle malgré ses contributions importantes à la mise en œuvre du projet réformiste qui, entre autres, a permis la consolidation de l'État lä̈que. Mexicain. Cependant, son activité politique a été reléguée au second plan par l'historiographie traditionnelle et ses travaux n'ont pas encore suscité l'intérêt des chercheurs. Précisément, parmi ses nombreuses productions, se distingue ce discours qu'il a présenté devant la session plénière de la Cour suprême de justice et avec lequel il a non seulement obtenu une résolution favorable à la demande de protection de Faustino Goribar mais a également jeté les bases de la justification de la Régime Tuxtepecan qui venait de prendre le pouvoir. Pour cette raison, l'objectif central de ce travail est d'examiner ladite allégation en utilisant les principes de l'herméneutique juridique et, de cette manière, de comprendre les ressources rhétoriques utilisées par Montes. Enfin, l'hypothèse qui sous-tend notre travail consiste à démontrer que, à ses débuts, le mouvement Tuxtepecan qui a conduit Porfirio Díaz à la présidence a été interprété par Ezequiel comme la dernière tentative de faire respecter pleinement le texte original de la Constitution fédérale. de I857, tel qu'il avait été modifié à différentes reprises par les administrations précédentes, qui n'hésitaient pas à recourir à des pouvoirs extraordinaires.

Mots-clés: Cour Suprême de Justice, révolution de Tuxtepec, protection, constitucion, pouvoirs extraordinaires.
Bezinteresowna przyjaźń? Porfirio Díaz, Ezequiel Montes i jego przemowa $z$ dnia 6 lipca 1877

\section{Streszczenie:}

W tym artykule analizujemy przemowe Ezequiela Montesa Ledesma, jednego $\mathrm{z}$ najmniej znanych liberalow $\mathrm{z}$ wieku XIX pomimo jego istotnego wkładu w realizację projektu reformy, który, między innymi, pozwolił na konsolidację meksykańskiego świeckiego państwa. Jego działalność polityczna do tej pory nie wzbudziła zainteresowania naukowców. Wśród jego roznorodnych dokumentow znajduje sie przemówienie, które wygłosił na sesji plenarnej Najwyższego Sądu Sprawiedliwości, z którym nie tylko uzyskał korzystną decyzję o wniosku o ochronę Faustino Goribara, ale także położył podwaliny pod uzasadnienie reżimu Tuxtepecan, który właśnie doszł do władzy. Z tego powodu głównym celem tej pracy jest zbadanie argumentu uzytego przez Montesa przy użyciu zasad hermeneutyki prawnej, a tym samym zrozumienie retoryki wykorzystywanych przez mowce. Wreszcie hipoteza, która leży u podstaw naszej pracy, polega na pokazaniu, że w pierwszych dniach ruch Tuxtepecan, który doprowadził Porfirio Díaza do prezydencji, został zinterpretowany przez Ezechiela jako ostatnia próba zapewnienia pełnego poszanowania pierwotnego tekstu konstytucji federalnej z I857 r., ktory był wielokrotnie modyfikowany przez poprzednia administracje korzystajaca z nadzwyczajnych uprawnień.

Slowa kluczowe: Suprema Corte de Justicia, konstytucja, nadzwyczajne decyzje. 


\section{Introducción}

En los últimos años, la dictadura porfirista ha sido objeto de una exhaustiva revisión por parte de los historiadores quienes, desde diferentes perspectivas, han examinado los cambios políticos, económicos, sociales y culturales ocurridos en el país desde su llegada a la presidencia en mayo de I877. Sin embargo, son pocos los trabajos que se han ocupado de los partidarios de Díaz y como estos le ayudaron a consolidar, en un primer momento, los principios anunciados en el Plan de Tuxtepec reformado en Palo Blanco (Ávila, Castellano y Pilar, 20I5; Carregha, Pérez y Ponce, 20I7).

Tal es el caso de Ezequiel Montes Ledesma, notable jurisconsulto de la época, quien en ese mismo año publicó el alegato que había presentado ante la Suprema Corte de Justicia, con el fin de obtener una resolución favorable a la solicitud de amparo de Faustino Goribar pero que, por la naturaleza del caso, le sirvió de base para justificar uno de los objetivos formulados por este movimiento, así como la pertinencia de aceptar a Porfirio Díaz en el poder. Este hecho, que a simple vista puede parecernos insignificante, resulta de vital importancia al momento de estudiar las relaciones que el militar mantuvo con los letrados y cómo estos percibieron su programa de gobierno, aspecto poco explorado por la historiografía.

Por esta razón, en el presente artículo estudiaremos dicho discurso y los elementos retóricos que utilizó su autor, a fin de conocer su interpretación de la revuelta tuxtepecana y, de este modo, comprenderemos sus planteamientos jurídicos.

74 Sin embargo, antes de pasar a nuestro estudio debemos explicar en qué consiste la hermenéutica jurídica, pues fue gracias a ella que pudimos entender el proceso mediante el cual Montes desarrolló su argumentación. Pues bien, la hermenéutica jurídica es la parte de la metodología del derecho que se encarga de interpretar las normas y leyes que rigen la sociedad en un momento determinado y en cuanto a su manifestación textual. Esta, a su vez, puede entenderse desde dos 
vertientes: como proceso y como producto. Para el caso que aquí nos ocupa, nos interesa resaltar el segundo aspecto porque este nos permite comprender el resultado del proceso cognitivo realizado por el intérprete de la ley, es decir, la manera en la que Ezequiel interpretó los artículos constitucionales a partir de sus conocimientos en materia de derecho legislativo.

En este sentido, es importante destacar el hecho de que el autor recuperó el sentido original de estas disposiciones, tal y como fueron promulgadas por primera vez en febrero de I857. De esta forma, al conocer el marco normativo a partir del cual el autor estructuró su discurso, podemos concluir que este es, en esencia, una jurisprudencia porque transmite las nociones que Montes tenía sobre el particular y la manera en la que este debía ser interpretado y aplicado (Hernández, 20I9).

De esta forma, derribaremos uno de los tópicos más recurrentes que surgen al investigar este periodo, el cual consiste en considerar que el general Díaz siempre demostró una total indiferencia hacia los intelectuales para quienes acunó la frase de "ese gallo quiere mais (sic)" dando a entender que la mejor manera de someterlos -y librarse de ellos- era dándoles un buen ingreso como empleados de la federación ${ }^{\mathrm{I}}$ (Garner, 2008; Cosío, 1970). Finalmente, las fuentes que utilizaremos para dar sustento a nuestra argumentación provienen, mayoritariamente, de la correspondencia personal de Ezequiel Montes, la cual ha sido cotejada y complementada con otros registros bibliohemerográficos. $^{2}$

Entre la legalidad y el militarismo. El problema de la sucesión presidencial en 1877

A principios de $\mathrm{I} 877$, continuaba la crisis política generada por las elecciones del año anterior. Como se recordará, el licenciado Sebastián Lerdo de Tejada, quien detentaba el Poder Ejecutivo desde I872, decidió reelegirse pese a su impopularidad, pues estaba empeñado en 
continuar con su proyecto de nación, el cual buscaba la aplicación directa de las Leyes de Reforma. ${ }^{3}$ Sin embargo, lo anterior no agradó a todos los sectores de la población y muy pronto surgieron grupos de oposición que buscaron frenar las aspiraciones del presidente y, de paso, terminar con la práctica de la reelección que, en opinión de muchos, era la responsable de los nuevos males que aquejaban a la República pues, además de contravenir con lo estipulado en la Constitución de 1857 , propiciaba el nepotismo, atentaba contra el libre ejercicio de la democracia y entorpecía el funcionamiento de los otros Poderes de la Unión y de las instituciones gubernamentales (Cosío, I970; González, 2000).

Ahora bien, los primeros en enfrentarse a Lerdo fueron los partidarios del general Díaz, quienes vieron en esta situación la oportunidad que necesitaban para hacerse con el poder, enarbolando para ello el principio de la no reelección y propugnando por el retorno a la observancia directa de la ley fundamental del país. Guiados por estos principios, procedieron a desconocer con antelación el resultado de las votaciones que tendrían lugar a mediados de 1876 y se lanzaron a la lucha armada proclamando el Plan de Tuxtepec, que luego fue reformado en la comunidad de Palo Blanco, en marzo de ese mismo año.

Dicho documento establecía, entre otras cosas, que los comicios para designar a las nuevas autoridades federales se organizarían una vez que la capital fuera ocupada por los rebeldes. Entretanto, el Poder Ejecutivo recaería, provisionalmente, en el presidente de la Suprema Corte de Justicia, quien no tendría mayores atribuciones que las meramente administrativas y debería entregar el mando al ciudadano que ganara 76 la elección. Sin embargo, antes de acceder a este cargo el magistrado en programa revolucionario y hacer pública su afiliación al movimiento tuxtepecano porque, de lo contrario, el gobierno quedaría en manos del jefe de armas que no era otro que Porfirio Díaz (Cosío, 1970). 
Como puede imaginarse, esta situación comprometió políticamente al licenciado José María Iglesias -entonces presidente del Poder Judicialquien tuvo que hacer frente a esta disyuntiva: apoyar a Díaz o permitir la reelección de Lerdo. Por un lado, Iglesias desconfiaba del grupo tuxtepecano, pues los consideraba meros oportunistas, a la vez que temía los excesos que pudieran derivarse del conflicto armado. Por el otro, tampoco estaba de acuerdo con la reelección de Lerdo, pues todo parecía indicar que el mandatario y sus seguidores amañarían las elecciones con tal de perpetuarse en el poder, dando lugar a la formación de un gobierno ilegítimo. Ante este panorama, el magistrado optó por oponerse a Lerdo mediante la vía constitucional pensando en que, si lograba frustrar sus intenciones, la Revolución de Tuxtepec quedaría invalidada (Cabrera, 1989).

Tras la celebración de los comicios, resultó evidente que el mandatario obtendría la mayoría necesaria para garantizar su permanencia en el cargo, a pesar del abstencionismo y de que en algunas ciudades se decretó estado de sitio. Con todo, Iglesias decidió esperar los resultados oficiales para poder actuar y cuando supo que Lerdo había obtenido la victoria, publicó un manifestó en donde denunció los abusos y las irregularidades que se habían cometido a lo largo del proceso electoral, demostrando así su invalidez. Por esta razón, se autodesignó presidente interino constitucional de la República Mexicana y fue reconocido como tal por los gobernadores de Aguascalientes, Querétaro, Guanajuato y Tlaxcala (Cabrera, I989; Quirarte, 1998).

Mientras tanto, las fuerzas tuxtepecanas derrotaron al ejército federal en la batalla de Tecoac, el I6 de noviembre de I876, propiciando con ello la huida de Lerdo y su ministerio. Al cabo de algunos días de marcha, el exmandatario llegó a los límites del estado de Guerrero buscando el apoyo del gobernador Diego Álvarez y, al no encontrar las condiciones necesarias para proseguir la lucha, decidió embarcarse con destino a los Estados Unidos. A partir de este momento, la pugna por la sucesión presidencial se limitaría a los dos bandos activos: los iglesistas y los tuxtepecanos quienes, sin pérdida de tiempo, ocuparon la capital y procedieron a nombrar un nuevo gabinete, pues su intención era que 
se organizaran las elecciones lo antes posible. Por su parte, Díaz trató de llegar a un acuerdo con Iglesias y, al agotarse las negociaciones telegráficas, accedió a entrevistarse con él en la Hacienda de La Capilla ubicada en Querétaro, delegando la presidencia a uno de sus subalternos, el general Juan N. Méndez (Cosío, 1970).

No obstante, los esfuerzos por llegar a un entendimiento resultaron infructuosos y no hubo más remedio que resolver la cuestión por medio de la vía armada. Así comenzó el año de i877 y tanto la prensa como la opinión pública estaban al pendiente del desarrollo de estos acontecimientos. ${ }^{4}$ Con todo, la balanza política pronto se inclinaría a favor de los tuxtepecanos porque su movimiento permitía la incorporación de los grupos desplazados por Lerdo y de aquellos que eran contrarios a la postura de Iglesias quien, al agotarse sus recursos económicos, también decidió embarcarse rumbo a los Estados Unidos, permaneciendo en aquel país hasta el mes de octubre, fecha en la que decidió volver a México y vivir apartado de la política por el resto de sus días (Cosío, 1970).

Libres ya "de la odiosa tiranía de Lerdo y de las vanas pretensiones de Iglesias” (Cosío, I970, p. 150), el gobierno revolucionario terminó de organizar las elecciones que habrían de legitimar a las nuevas autoridades federales. Además, se dio a la tarea de reactivar los negocios públicos suspendidos tras la revuelta y buscó afanosamente el reconocimiento diplomático de los Estados Unidos, para evitar cualquier amenaza que pudiera provenir de los grupos exiliados en aquel país, mismos que fueron estrechamente vigilados por los agentes de Díaz.

Sin embargo, tras el entusiasmo inicial, comenzaron las críticas hacia el gobierno, pues los opositores señalaron su ilegitimidad y su falta de experiencia al no contar con un proyecto de nación a largo plazo. Por si fuera poco, la facción lerdista seguía activa en el país y pronto adquiriría nuevos bríos cuando se conoció el manifiesto de Lerdo de Tejada, fechado en Nueva York el 24 de febrero de I877, en el cual justificó su mandato y las acciones emprendidas durante la revuelta, culpando a 
Iglesias de la división interna que afectó la lealtad de sus partidarios. Por último, reiteró su posición como "presidente constitucional de los Estados Unidos Mexicanos" afirmando que la distancia no sería un impedimento para el cumplimiento de sus deberes (La Linterna, I877).

Para los detractores de la Revolución de Tuxtepec, este documento marcó el inicio de la campaña militar que acabaría con el régimen, permitiendo al país retomar los cauces de la legalidad y el constitucionalismo. De esta forma, a los pocos meses de conocerse esta declaración, surgieron los primeros levantamientos que, aunque no tuvieron el éxito esperado, si generaron alarma y desconcierto entre la población, convirtiéndose en un problema más para la administración porfirista. Por su parte, los debates en la prensa fueron tan acalorados que se llegó a pensar que la caída de Díaz era sólo cuestión de tiempo, lo cual pareció confirmarse cuando se supo que el general Mariano Escobedo, antiguo ministro de Guerra y uno de los colaboradores más cercanos a Lerdo, alistaba una incursión militar a gran escala desde la frontera sur de los Estados Unidos, con el propósito de rehabilitarlo en el poder (Cosío, 1970).

Estos fueron algunos de los obstáculos que Porfirio Díaz tuvo que afrontar en su primer año de gobierno, a lo que pronto se sumó la división interna de su gabinete y la necesidad de mejorar la imagen pública que se tenía de su administración pues, exceptuando a sus partidarios, el resto de la sociedad consideraba a Díaz como un advenedizo que había obtenido el poder por medio de la fuerza y el rompimiento de la legalidad, confirmando así su falta de escrúpulos (Garner, 2008). Afortunadamente, algunos de sus simpatizantes se dieron a la tarea de justificar el nuevo ordenamiento político, labor en la que destacó el licenciado Ezequiel Montes Ledesma. 


\section{Un defensor de la legalidad. Ezequiel Montes Ledesma frente a las revueltas porfiristas}

Nacido en Cadereyta, Querétaro, el 25 de noviembre de I820, Montes formó parte de la generación que reconstruyó al país luego de la guerra con los Estados Unidos. A los I8 años, ingresó al Nacional y Más Antiguo Colegio de San Ildefonso en donde estudió teología y jurisprudencia. Gracias a sus redes familiares, obtuvo una diputación en el Congreso Estatal de Querétaro y, más adelante, representó a su entidad en el Congreso Federal de i852. Fue en dicha legislatura donde conoció a la mayor parte de los individuos que, años más tarde, habrían de impulsar el proyecto de Reforma. Entre estos se encontraban Guillermo Prieto, Manuel Doblado, Miguel María Arrioja, Mariano Yáñez e Ignacio Comonfort. Su amistad con este último le permitió formar parte de los gobiernos emanados de Ayutla, siendo nombrado por el propio Comonfort como Ministro Plenipotenciario de México ante El Vaticano en abril de I857 (Bonilla, I873). ${ }^{5}$

Sin embargo, el estallido de la Guerra de los Tres Años interrumpió su misión diplomática en Europa, por lo que tuvo que regresar y retomar sus negocios particulares. En I86I se incorporó a las labores parlamentarias de la Segunda Legislatura Federal y fue ahí donde conoció al joven Porfirio Díaz, quien acababa de ser nombrado diputado federal por el distrito de Ocotlán. A partir de este momento, comenzaría la amistad entre ambos personajes, la cual se consolidó en la época de la Intervención, luego de que Díaz le confiara su defensa jurídica tras ser capturado en la ciudad de Oaxaca, por las tropas del mariscal Aquiles Bazaine, en febrero de I865 (Montes, I877).

80 Con todo, Ezequiel no tuvo oportunidad de ayudarlo ya que el militar logró fugarse de sus captores y proseguir la lucha en contra del Imperio, en el estado de Guerrero, bajo el amparo del general Juan Álvarez. Por su parte, Montes trató de permanecer al margen de los acontecimientos políticos mientras duró la Intervención, pero de nada le sirvió porque, en septiembre de I866, fue detenido de manera arbitraria en su domicilio y, sin formación de causa, condenado al exilio en Francia, en 
donde permaneció hasta la caída de Habsburgo en junio de 1867 (Bonilla, I873).

A su regreso, le fue notificada su designación como magistrado de la Suprema Corte de Justicia, pero Ezequiel rechazó este nombramiento para ocupar, de nueva cuenta, un lugar dentro del Congreso Federal. Allí llegó a ser presidente, correspondiéndole el honor de contestar el discurso pronunciado por Juárez el 8 de diciembre de ese mismo año, con motivo de la apertura de sesiones. En esa ocasión, Montes resaltó el apoyo y la participación de los generales que habían permanecido fieles a la República porque, en su opinión, "[ellos] lucharon contra el invasor y contra sus aliados y hoy son un modelo de fidelidad a las instituciones y de obediencia al Presidente" (Bonilla, I873, pp. 5-12), siendo Porfirio Díaz uno de los aludidos quien, por su parte, se retiró a Tehuacán después de recibir el grado de Comandante en Jefe de la División de Oriente (Soto, I985).

En los años siguientes, Montes trabajaría en la Comisión de Puntos Constitucionales mientras que Díaz viviría un periodo de relativa tranquilidad al lado de su familia, lo cual no fue un impedimento para el desarrollo de sus redes políticas. Con el paso del tiempo, estas crecieron y se multiplicaron hasta conformar la Asociación Democrática Constitucional, cuyo órgano de difusión, el periódico $E l$ Mensajero, decidió postularlo como candidato presidencial en enero de I87I para terminar, de una vez por todas, con el largo gobierno de Juárez (Montes, I877).

Con todo, la Asociación no pudo lograr su objetivo y, tras las votaciones, resultó claro que Juárez conservaría el poder por un periodo más. $\mathrm{Al}$ percatarse de esta situación, Ezequiel le escribió una carta a Porfirio Díaz para aconsejarlo y prevenirlo de los terribles males que traería al país el surgimiento de un nuevo movimiento armado. Esto, porque dentro de la agrupación habían surgido dos tendencias antagónicas: por un lado, estaban los que querían "el triunfo de sus principios y de su candidato por los medios constitucionales y pacíficos" y, por el otro, "los 
que querían el mismo triunfo por medio de una revolución" (Díaz, I95I, pp. 25I-255).

Y ya que el general había dado muestras de tener "un buen sentido político y una honradez y lealtad a los principios constitucionales", Montes estaba seguro de que preferiría la vía legal para acceder a la presidencia y de ninguna manera apoyaría este levantamiento. En su opinión, la mejor forma de detener la reelección era organizando una liga parlamentaria con los lerdistas, pues esto generaría un equilibrio de fuerzas dentro del Congreso, convertido en colegio electoral, y cuyos objetivos serían los siguientes:

$\mathrm{I}^{\mathrm{a}}$ obligación del partido lerdita de votar en favor de la presidencia de usted, competidor de Juárez, y

$2^{\text {a }}$ obligación del partido porfirista de considerar a su aliado como igual suyo, por consiguiente, los lerdistas tendrán el mismo derecho que los porfiristas a todos los oficios y puestos públicos (Montes, I877, pp. 120-I25).

De este modo, la sucesión presidencial sería aplazada, se convocarían a nuevas elecciones y no habría necesidad de alterar el orden ni la paz pública.

Sin embargo, y contra todo pronóstico, Díaz prefirió el camino de las armas para hacerse con el poder. Así, en noviembre de ese mismo año proclamó el Plan de La Noria, el cual no tuvo mucho éxito y pronto sería derrotado por el ejército federal (Perry, 1996). Por su parte, Montes decidió permanecer al margen de los acontecimientos bélicos sin perder por ello contacto con Díaz y sus allegados, en especial con el

82 general Manuel González, quien le otorgó plenos poderes para que pudiera defenderlo jurídicamente ante cualquier eventualidad. ${ }^{6}$ En dicha ocasión, Montes tuvo la oportunidad de demostrar su valía como abogado, ya que pudo recuperarle varias de las propiedades que le habían sido confiscadas a causa de su participación en el movimiento armado (Olivera, 2019). 
Tal era el panorama que prevalecía en el país cuando, el i 8 de julio de I872, sobrevino la muerte de Juárez a causa de un paro cardiaco. Este hecho provocó que las atribuciones del Ejecutivo fueran transferidas, provisionalmente, al licenciado Sebastián Lerdo de Tejada quien, entre otras cosas, decretó un cese al fuego con los alzados y convocó a nuevas elecciones en las que obtuvo un triunfo avasallador. Gracias a esto, quedó investido con el cargo de presidente constitucional el $\mathrm{I}^{\circ} \mathrm{de}$ diciembre de ese mismo año (Perry, 1996).

Así concluyó la primera rebelión antirreeleccionista y, tras un breve periodo en la capital, Díaz optó por retirarse a la región de Tlacotalpan, para dedicarse al cultivo de la caña de azúcar. Finalmente, el general volvería a la escena pública en enero de 1876 para buscar, de nueva cuenta, la presidencia del país. Durante todo ese tiempo, Ezequiel alternó sus ocupaciones parlamentarias con las de la práctica jurídica hasta que, en julio de I873, resultó electo décimo magistrado de la Suprema Corte de Justicia (Serrano, 20I2; Olivera, 2019). A diferencia de otras ocasiones, Montes aceptó este cargo, pero no pudo incorporarse inmediatamente a las labores del Poder Judicial en ese año, debido a sus problemas de salud, teniendo que postergar su ingreso hasta mayo de I875. Para esas fechas, las medidas anticlericales de Lerdo habían generado un grave descontento en diversas zonas del Bajío y Michoacán, cuya población se levantó en armas para defender su identidad católica. Al percatarse de que las revueltas no podían ser sofocadas tan fácilmente, el mandatario siguió la misma línea de su predecesor y no dudó en solicitar el uso de facultades extraordinarias al Congreso. De este modo, pudo legislar libremente en los ramos de Hacienda y Guerra, así como suspender las garantías individuales en los territorios rebeldes (Pi-Suñer, 2008; Ochoa, 2003).

Con tales atribuciones, Lerdo de Tejada dictó las medidas que creyó necesarias para terminar con los rebeldes y, tras el estallido del movimiento tuxtepecano, solicitó que estas fueran ampliadas por tiempo indefinido. Ahora bien, entre las leyes que causaron mayor controversia por su arbitrariedad estaban: la de los conspiradores y la de contribución extraordinaria sobre capitales. En el primer caso, 
bastaba una denuncia para que alguien fuera acusado de conspirador y acabara encarcelado e incomunicado por varios días, mientras se resolvía su situación jurídica. En cambio, la segunda medida se promulgó con el objetivo de incrementar los ingresos fiscales, pues estos serían utilizados para financiar la campaña en contra de Díaz. Por esta razón, el mandatario gravó con un impuesto, que iba del medio hasta el uno por ciento, todos los capitales existentes en el territorio nacional, incluyendo los vales, libranzas, propiedades rústicas y urbanas, así como los giros mercantiles e industriales (Dublán y Lozano, I898).

En la práctica, estas medidas resultaron infructuosas y fueron señaladas por la prensa de oposición como una prueba más "del gobierno despótico de Lerdo". Por su parte, los ciudadanos que se vieron afectados directamente no dudaron en solicitar el recurso de amparo ante la Suprema Corte de Justicia, argumentando que dichas disposiciones violentaban las garantías individuales consagradas en la Constitución. Sin embargo, el Poder Judicial fue incapaz de atender todas las solicitudes porque, en noviembre de I876, el Ejecutivo ordenó la detención de los magistrados que estuvieran bajo sospecha de apoyar políticamente a José María Iglesias o a Porfirio Díaz, provocando con ello la suspensión de actividades del máximo tribunal. Tuvieron que pasar varios meses antes de que el régimen tuxtepecano rehabilitara a la Corte, lo que finalmente sucedió en junio de I877 (Cabrera, 1990).

Durante todo ese tiempo, la salud de Montes se deterioró a tal punto que en repetidas ocasiones tuvo que pedir licencia para ausentarse de la ciudad y retirarse a Taxhidó, ${ }^{7}$ un manantial cercano a la población hidalguense de Tecozautla, en donde había construido unos baños de tipo romano, aprovechando las aguas medicinales de ese lugar (Peñafiel, I9II). De ahí que su participación en la revuelta haya sido breve, limitándose a ser un mediador más entre los jefes revolucionarios. A pesar de todo, Ezequiel no renunció a su magistratura y aún tuvo el ánimo necesario para competir por la presidencia de la Corte, perdiendo las elecciones frente al abogado jalisciense Ignacio Luis Vallarta Ogazón (Cabrera, 1990). 
Como mencionamos anteriormente, el restablecimiento del Tribunal permitió la reactivación de los asuntos judiciales que habían quedado pendientes desde noviembre de 1876 , entre los que se encontraba el juicio de amparo promovido por el empresario Faustino Goribar, cuyo patrimonio se vio afectado por la Ley de Contribución Extraordinaria. ${ }^{8}$ En efecto, luego de que el director de la Oficina de Contribuciones Directas del Distrito Federal se percatara de que los ingresos declarados por Goribar eran insuficientes para cubrir la cuota estipulada por el Poder Ejecutivo, decretó el embargo de sus bienes con la finalidad de obtener la cantidad correspondiente. Ante esta situación, el afectado solicitó la revocación de la orden al juzgado $\mathrm{I}^{\circ}$ de la capital argumentando que, de efectuarse, la autoridad atentaría contra las disposiciones contenidas en los artículos I6 y 27 constitucionales (La Patria, I877, Faustino Goribar).

A pesar de que el empresario contaba con el asesoramiento del licenciado Manuel Morquecho, su petición fue declarada improcedente por la judicatura ya que, para los jueces, el cumplimento de esta medida iba acorde con la legislación creada por el mandatario en virtud de las facultades extraordinarias, las cuales no podrían ser abolidas a corto plazo debido a la revuelta tuxtepecana. Y antes de que Goribar pidiera la rectificación de la sentencia, se suspendieron las actividades del Poder Judicial y el caso no volvió a ser examinado sino hasta julio de I877 por el pleno de la Suprema Corte. Para este momento, el juicio de Goribar había adquirido el carácter de una controversia constitucional, pues el argumento central se limitaba a lo siguiente: ¿puede el Ejecutivo legislar en materia de Hacienda por el simple hecho de estar investido por facultades extraordinarias? y, si este era el caso, ¿sería procedente la solicitud de amparo por parte de los afectados? (AHSCJN. [Archivo Histórico de la Suprema Corte de Justicia de la Nación], I877, Tribunal Pleno).

Esta fue la cuestión que se discutió en el Tribunal, dando a Montes la oportunidad de pronunciar la primera versión de su discurso, el cual acabó favoreciendo la solicitud de amparo de Goribar. Viendo el éxito de su alegato, Montes decidió escribir una versión más acabada del 
mismo y desarrollar ahí sus ideas principales con la finalidad de que estas dieran mayor sustento al régimen tuxtepecano cuyo jefe, el general Díaz, había asumido entretanto el cargo de presidente constitucional en mayo de ese mismo año. ${ }^{9}$

\section{El Discurso del 6 de julio de 1877 o la conveniencia de aceptar a Díaz como presidente}

Pero este no era el único objetivo que perseguía Montes, ya que también buscaba refutar a sus detractores que llevaban años cuestionando su postura política y su permanencia dentro del Poder Judicial. Y es que, para este momento, su labor proselitista sería interpretada de diferente manera, dependiendo la edad de sus lectores. Para los liberales que habían participado en la Guerra de los Tres Años Ezequiel representaba el paradigma del orador parlamentario, cuyo conocimiento del latín y habilidades para la oratoria le valieron el sobrenombre de El Profeta, pues "sus visiones políticas" eran comparables con las del personaje bíblico. Para la nueva generación educada bajo los principios del positivismo, Montes no pasaba de ser "una reliquia" porque se había estancado en la etapa "metafísica" del desarrollo jurídico al seguir sustentando sus opiniones en los "dogmas y abstracciones" provenientes del derecho romano, que poco o nada tenían que ver con la realidad mexicana. Por si fuera poco, muchos pensaban que su enfermedad era la responsable "de la pérdida de sus facultades mentales" por lo que más de uno sugirió que "el Sr. Lic. Montes, después de haber llegado a la cúspide de su carrera jurídica, ya no sabe lo que dice y debe comenzar de nuevo los estudios sin omitir el curso de gramática española". Io

Como puede imaginarse, estas opiniones influirían en la elaboración de este discurso, cuyo proceso de redacción comenzó la tarde en la que Montes recopiló los materiales que necesitaba de su biblioteca, los cuales dividió en dos partes: por un lado estaban las obras que versaban sobre teoría jurídica y derecho constitucional y, por el otro, el cuestionario que envió a los diputados que participaron en la 
elaboración del Código fundamental de I857, a quienes formuló las siguientes preguntas: “¿puede el Poder Legislativo delegar todas o algunas de sus facultades al Poder Ejecutivo?” o, dicho en otras palabras, “¿puede el presidente de la República estar autorizado para dar leyes, en los casos a que se refiere el artículo 29 constitucional?" (Olivera, 20I9, reg. 957).

Cuando hubo reunido todo esto, Ezequiel solicitó una nueva licencia por enfermedad a la Suprema Corte de Justicia, argumentando que sus doctores le habían recomendado "cambiar de aires y abstenerme de trabajos intelectuales serios, o que preocupen el espíritu para recuperar la salud". Por tal motivo, el magistrado decidió retirarse a la localidad hidalguense de Huichapan, en donde vivía su hermana menor Dolores Montes Ledesma (AHSCJN, I877, Asuntos económicos).

De esta forma, Montes abandonó la capital en los primeros días de septiembre de 1877 y para mediados de mes tenía listo su discurso, el cual dio a la imprenta de Francisco Díaz de León ${ }^{\text {II }}$ (Olivera, 2019). Y mientras esperaba la remisión de los ejemplares, el magistrado se dio tiempo para visitar a sus parientes que vivían en los alrededores a la par de frecuentar los baños de Taxhidó. Finalmente, en noviembre de ese mismo año recibiría los primeros ejemplares de su discurso, donando algunos al Archivo Municipal de Cadereyta, como muestra de aprecio al lugar donde nació. Otros tantos los regalaría a sus amigos más cercanos, incluido Guillermo Prieto, a quien le dedicó el ejemplar que actualmente resguarda el Fondo Reservado de la Biblioteca Nacional de México y el cual hemos utilizado para realizar nuestro análisis (Moctezuma, 1994). ${ }^{\text {I2 }}$

Una vez dicho esto, pasemos a la descripción física del documento, el cual consiste en un cuadernillo en formato de cuarto mayor, cuyo texto está dividido en tres partes: en la primera, encontramos la carta que, a manera de dedicatoria, Ezequiel le escribió a Díaz anunciándole la redacción de su discurso. En la segunda, el magistrado desarrolla sus ideas políticas a partir de la petición de amparo de Faustino Goribar, siendo esta la parte más importante. Finalmente, el texto cierra con la 
transcripción de las repuestas de los abogados a quienes Montes consultó sobre los límites de las facultades extraordinarias que podían ser otorgadas a un presidente, lo cual nos da un total de I47 páginas.

Por otra parte, hay que tener en cuenta que, para la redacción de su discurso, Montes utilizó el modelo retórico ciceroniano, el cual estipula que la Historia debe ser la principal herramienta del orador, ya que el conocimiento del pasado proporciona los ejemplos necesarios para fundamentar cualquier argumento que la situación requiriese, debido a su condición de ser la magistra vitae (esto es, la maestra de la vida) por excelencia. ${ }^{\mathrm{I} 3}$ De esta forma, uno de los rasgos característicos que encontraremos a lo largo de la obra es la constante comparación entre el pasado y el presente. Como veremos más adelante, la hipótesis central de su trabajo consiste en demostrar que el régimen político creado en México, a partir del uso de las facultades extraordinarias, es más arbitrario y despótico que cualquier dictadura que se halla proclamado en tiempos de la República romana ya que, contrario a lo que pudiera pensarse, en esta jamás se concentró el poder público en una sola persona.

Luego de demostrar dicha suposición, lo que le interesa a Montes es convencer a sus lectores de que lo más conveniente para el país es aceptar la permanencia del grupo tuxtepecano porque este ha sido el único que, desde sus orígenes, ha defendido el predominio absoluto de la Constitución, convirtiéndose en el eje central del nuevo gobierno. Para Ezequiel, esta sería una de las razones que explicarían el triunfo electoral de Díaz pues, por primera vez en muchos años, el pueblo mexicano tuvo la oportunidad de manifestarse libremente y elegir a los representantes federales que consolidarían la paz y la restauración del 88 orden constitucional.

Pero ¿qué decir de los detractores quienes señalaban, precisamente, la ilegalidad de este acto por estar basado en un movimiento revolucionario? Para Montes, la pregunta carece de sentido porque la revuelta que destituyó a Lerdo de Tejada se hizo, precisamente, para terminar con la tiranía que este ejercía. Por lo tanto, esta acción es, en sí 
misma, la aplicación "del derecho inalienable" que tienen todos los pueblos para sacudirse las injusticias de que son objeto, principio que es reconocido incluso por los grandes juristas ingleses y norteamericanos tan contrarios a la tradición hispánica. Por esta razón, no duda en afirmar que quienes así se expresan están condenando, sin saberlo, la emancipación de las naciones americanas (Montes, I877).

Finalmente, el autor termina su dedicatoria expresando sus esperanzas respecto al gobierno de Díaz quien, en su opinión, "será el encargado de terminar con el cesarismo y la dictadura que impera en el país" pues su gran mérito es ser un soldado del pueblo. Con ello, México se convertirá en una nación civilizada y dejará de ser, por fin, "el país de lo imprevisto" (Olivera, 20I9). ${ }^{\mathrm{I}}$

Dicho esto, pasemos a examinar este discurso, el cual comienza con una cita de la proclamación del Plan de Tuxtepec, reformado en Palo Blanco por Díaz en marzo de I876, en la que se establece que este documento "será la regla invariable que norme nuestros actos, mientras la Nación se pone en actitud de sustituirlo, con la observancia neta de la Constitución" (subrayado de Montes). A continuación, Ezequiel afirma que "la gravedad y el interés social de las cuestiones constitucionales" que va a analizar "son superiores a cualquiera que se hayan presentado" desde que él tomó posesión de su magistratura en mayo de i875 porque, durante ese periodo, las circunstancias políticas obligaron al presidente en turno a solicitar el uso de facultades extraordinarias, sin reparar en los graves daños que esto traería a los ciudadanos mexicanos, como lo demuestra el caso de Faustino Goribar (Montes, I877, pp. I-3). ${ }^{15}$

Por ello, en las siguientes líneas explicará porque votó a favor de la solicitud de amparo, haciendo un examen minucioso de los orígenes de la dictadura romana, señalando sus alcances y limitaciones. Después, comparará esta forma de gobierno con las que han sido implementadas en el país, luego de la promulgación de la Constitución federal de I857. Por último, exaltará al movimiento tuxtepecano porque, en su opinión, este terminará con el ciclo de las tiranías que han regido a México. 
Ahora bien, siguiendo la máxima expresada por Montesquieu, quien en El espíritu de las leyes afirmó que todo principio político "es más fuerte cuando se tienen a los romanos a su favor", Ezequiel inicia su alegato evocando el pasado de dicho pueblo "que no sólo dominó con las fuerzas de las armas" al mundo por entonces conocido, sino que continúa siendo "el maestro del género humano en la ciencia de la legislación”. Para muestra, basta la síntesis hecha por Tácito respecto al desarrollo de Roma:

Reyes gobernaron a Roma desde el principio: Lucio Bruto instituyó la libertad y el consulado, las dictaduras eran temporales, el poder decenviral no duró más de dos años, ni se sostuvo largo tiempo el derecho consular de los tribunos militares, ni la dominación de Cina ni la de Sila fueron largas; y el poder de Pompeyo y Craso recayó pronto en César: las armas de Lépido y Antonio recayeron en Augusto (Montes, I877, pp. 3-5).

Y a pesar de que la dictadura fue la máxima figura de autoridad que conocieron los romanos - pues la persona investida con tal poder podía controlar la libertad, el honor e incluso la vida misma de los ciudadanos- esta nunca pudo expedir leyes (subrayado de Montes). En consecuencia, el autor llega a la conclusión de que es absurdo pretender que el presidente de México, sin ser la sombra del dictador romano, pueda legislar libremente y sin ningún control sólo por estar investido por facultades extraordinarias (Montes, I877).

Por si fuera poco, los dictadores siempre dieron muestras de civilidad, al menos hasta la llegada de Lucio Cornelio Sila al poder, y nunca abusaron de su autoridad como lo demuestra el proceder de Tito Larcio Flavo quien, además de ser el primero en obtener este cargo, no mató, ni

90 causó grave mal a ningún ciudadano (subrayado de Montes) según nos cuenta Dionisio de Halicarnaso en su Historia. Desde ese momento, todos aquellos individuos que recibieran dicha dignidad seguirían el ejemplo de Flavo de suerte que el pueblo romano llegó a considerar que la dictadura era el remedio universal para cualquier mal que aquejará a la res pública (Montes, I877). 
Tras referir otras anécdotas sobre los autócratas, Ezequiel concluye lo siguiente: "I ${ }^{\circ} Q u e$ el pueblo romano no delegaba al dictador el poder legislativo, $2^{\circ}$ que el dictador no era un rey absoluto y $3^{\circ}$ que no residía en el dictador todo el imperio y todo el consejo de la República" (subrayado de Montes). Entonces, ¿por qué se piensa que la dictadura consiste en la concentración de los poderes públicos en una sola persona? Porque, prosigue el autor, "se ha confundido esta palabra con el silaismo y el cesarismo", ya que tanto Lucio Cornelio Sila como Cayo Julio César fueron los únicos "que usurparon la soberanía romana, arrogándose el Poder Legislativo y cometiendo todo género de crímenes para obtener el mando y perpetuarse en él" (Montes, I877, pp. 20-29).

De esta forma, el cargo que antes era otorgado por los Cónsules, el Senado o el pueblo bajo ciertas circunstancias especiales y cuya duración no sobrepasaba los seis meses, acabo convirtiéndose en una imposición producto de la violencia que corrompía tanto a las legiones como a las instituciones, teniendo los ciudadanos que soportar las arbitrariedades del gobernante hasta que este falleciera o fuera depuesto. Por lo tanto, si se quiere examinar la naturaleza del régimen político que se creó en el país con motivo de las facultades extraordinarias, primero se debe tener en cuenta el sentido original de esta palabra y el contexto que permitió su desarrollo en la República romana (Montes, I877).

Una vez hecho esto, el siguiente paso consiste en examinar si el Congreso Constituyente de 1856 estableció las condiciones necesarias para la formación del cesarismo y, de ser así, cual fue el modelo que siguieron los legisladores y que sentido pensaban darle a esta forma de gobierno en un primer momento. Para lograrlo, Montes comienza reseñando los acontecimientos que antecedieron a la promulgación del Plan de Ayutla reformado en Acapulco y como esto preparó el camino para la instalación del Constituyente.

Ahora bien, en una de sus primeras sesiones, el diputado Isidro Olvera planteó la posibilidad de otorgarle facultades extraordinarias al Ejecutivo "para que el gobierno de la República tenga, en las situaciones 
que lo ameriten, toda la acción necesaria para conducir como buen piloto la nave del Estado a puerto seguro" tal y como habían procedido los dictadores en la antigüedad. Sin embargo, a diferencia del razonamiento de Ezequiel, este legislador consideró que dicho sistema tuvo sus orígenes en el carácter innato de los romanos ya que, en su opinión, los primeros habitantes de la región del Lacio "fueron bandidos de profesión y se acostumbraron, por lo mismo, a obedecer a un capitán" (Montes, I877, pp. 35-37).

Y para evitar los posibles males que pudieran derivarse del uso indiscriminado de dichas facultades, Olvera propuso las siguientes medidas: que el Congreso fuera el encargado "de prever los únicos casos en que la dictadura pudiera ser indispensable, dificultando con ello cualquier intento de usurpación de los poderes públicos y entregándolos sólo a quienes el pueblo llamase a ejercerlos". En cuanto a las atribuciones, estas "deberían limitarse a un solo ramo puesto que todos los de la administración están naturalmente enlazados” por lo que "las facultades deberán ser generales y sin más reserva que el respeto a la soberanía de los Estados, a su forma de gobierno interna y a la defensa de la Independencia de la República”. En suma, el régimen que se formase con tales prerrogativas tendría una duración limitada y quedaría supeditado a las disposiciones de las legislaturas que lo precedieran y sucedieran. Tal fue el carácter del proyecto de adición a la fracción XXX del artículo 72 constitucional presentado por este diputado (Montes, I877, pp. 37-40).

A pesar de que la iniciativa pasó a comisiones, esta no se aprobó y, en su lugar, se presentó una adición al artículo 34 constitucional, el cual establecía la suspensión de las garantías individuales (subrayado de Montes)

92 en el momento en que el Congreso "concediera al gobierno las autorizaciones necesarias para hacer frente al peligro que amagare a la sociedad". Tras la discusión correspondiente, el texto fue aprobado por mayoría de votos.

Por su parte, el presidente Ignacio Comonfort envió una iniciativa a los parlamentarios, la cual contemplaba la suspensión de las garantías 
individuales y la facultad de que el Ejecutivo pudiera legislar libremente en los ramos de Hacienda y Guerra cuando la situación lo ameritase. Sin embargo, su propuesta no pasó el dictamen porque las diversas comisiones demostraron que este documento, en sí mismo, era incompatible con el espíritu que animaba al Constituyente, cuyo fundamento y principios seguían los postulados del Plan de Ayutla reformado en Acapulco (Montes, I877).

Entonces, ¿cómo fue posible que se conciliaran estas dos posturas dentro del Congreso si, por un lado, este tenía la obligación de constituir a la Nación mexicana bajo la forma de República democrática representativa (subrayado de Ezequiel) y, por el otro, se pedía el establecimiento de una dictadura que permitiera suspender las garantías individuales a la vez de conceder facultades omnímodas al mandatario en turno? Para Montes, la respuesta se encuentra en los acontecimientos que siguieron a la promulgación del código fundamental y no en las labores parlamentarias propiamente dichas, pues estas "nunca traicionaron su noble y elevada misión de sustituir el despotismo con el gobierno de la ley".

Lo que pasó fue que los legisladores aprobaron el artículo 29 bajo el entendido de que este sólo concerniría a la suspensión de las garantías individuales contempladas en la sección $\mathrm{I}^{\circ}$ del título I, refutando así la proposición presentada por el diputado Olvera. Por lo tanto, Montes concluye que:

El Poder Legislativo sólo concedió al Ejecutivo lo que expresamente le permite la constitución, siendo esta la que lo faculta para concederle las autorizaciones que estime necesarias para hacer frente a cualquier situación; pero esto no le autoriza para delegarle parte o la totalidad del Poder Legislativo [...] Por lo tanto, se pueden otorgar al [presidente] todas las autorizaciones que el gabinete y las comisiones de puntos constitucionales y de gobernación estimen necesarias «para proveer a la conservación a las actuales instituciones, a la defensa de la Independencia nacional y al restablecimiento del orden público» pero no se puede otorgarle la capacidad que es propia del Legislativo (Montes, I877, pp. 45-49). 
Dicho principio fue reafirmado en otros artículos de la Constitución e incluso pensadores de la talla de John Locke y Thomas M. Cooley han defendido esta idea pues "la facultad conferida al Poder Legislativo para hacer las leyes no puede ser delegada a ningún otro cuerpo o autoridad". Finalmente, y para darle mayor sustento a su argumentación, Montes compara la crisis política que ha padecido México desde I857 con la Guerra de Secesión en los Estados Unidos y concluye que, a pesar de que esta última fue más terrible y estaba en juego algo tan preciado como la dignidad humana, no por eso "el presidente Lincoln [se arrogó] la capacidad de legislar libremente por un solo día" (Montes, I877, p. 52). ${ }^{\mathrm{I}}$

Es en esta parte donde, gracias a la hermenéutica jurídica, podemos apreciar el proceso interpretativo que utilizó Montes para redactar su discurso, puesto que no sólo se limitó a explicar el sentido último de las disposiciones constitucionales sino que, al referir los acontecimientos históricos que permitieron su redacción, el autor tiene la posibilidad de comprender los alcances y objetivos que guiaron las acciones de los trabajos parlamentarios en el Constituyente de I856 y I857 pudiendo, de esta forma, articular su narración bajo el supuesto de que dichos artículos han sido mal interpretados y, lo que es peor, utilizados para justificar un régimen "metaconstitucional" porque sus atribuciones van más allá de las consignadas en el código fundamental. De esta forma, Ezequiel cumple con los postulados propuestos por Hernández para quien:

La hermenéutica jurídica [consiste] en la interpretación de las normas del derecho a partir de las conductas humanas y del contexto sujeto a ellas, cuyo fin es la revelación del sentido de su contenido con miras, principalmente, pero no de forma exclusiva, a su implicación en un caso concreto que permita llegar a una solución de los conflictos [jurídicos] llevados ante los juzgadores de una manera más eficaz, justa y razonable (Hernández, 20I9, p. 48).

Entonces, ¿por qué los “detractores de la legalidad” siguen insistiendo en que las facultades extraordinarias si fueron concedidas al Ejecutivo en los años posteriores a la Guerra de Reforma? Para Montes, esta 
pregunta representa un falso dilema ya que los opositores que así se expresan están mal interpretando el artículo 29 constitucional y olvidan las condiciones políticas que imperaban en esos momentos, pues tanto la Segunda como la Tercera Legislatura, de la que él formó parte, tuvieron que enfrentarse a la amenaza de la Intervención Francesa, lo cual fue aprovechado por Manuel Doblado para exigir que Juárez fuera investidos con tales atribuciones, bajo el argumento de que esto era un requisito indispensable para poder negociar con los líderes de la Expedición Tripartita, lo que dio como resultado la firma de los Tratados preliminares de la Soledad.

Por lo que respecta a los otros periodos parlamentarios, la concesión de las facultades extraordinarias fue una de las condiciones que el mandatario en turno impuso a los legisladores que buscaban garantizar su permanencia dentro de este poder, mediante la reelección indefinida, pues para nadie es un secreto que, en esos años, "los comicios federales eran controlados desde el Palacio Nacional" por los agentes de Juárez y de Sebastián Lerdo de Tejada. Esto, afortunadamente, ha cambiado gracias al triunfo del movimiento tuxtepecano, el cual impuso la libertad electoral. Por último, Montes insiste en la responsabilidad que tienen los magistrados de la Suprema Corte de Justicia para interpretar y recuperar el sentido original del artículo 29 que ha sido utilizado en muchas ocasiones para justificar prácticas leoninas. De no hacerlo, se estaría contraviniendo todas las disposiciones constitucionales y esto es contrario al interés público y a la máxima expresada por el licenciado José María Iglesias, quien sentenció que "SOBRE LA CONSTITUCIÓN NADA. SOBRE LA CONSTITUCIÓN NADIE” (Montes, I877, pp. 58-62). ${ }^{17}$

Por lo tanto, el movimiento tuxtepecano encuentra su propia justificación en el hecho de que fue este el que abrió la posibilidad para que la nación mexicana retome sus principios políticos fundamentales, contenidos en el Código federal de I857 y, al hacerlo, se respetaran "las garantías individuales, la soberanía nacional, la forma de gobierno republicano, representativo, democrático y federal, la división de poderes sin intervención de atribuciones entre las mismas potestades y 
la distribución del tesoro de acuerdo con las disposiciones vigentes y no mediante el capricho de los gobernadores". Esto, sumado al nuevo compromiso de hacer guardar las disposiciones constitucionales, "traerá la felicidad de la República". ${ }^{8}$

En suma, el Congreso Constituyente de I856 y I857 no creó “el cesarismo ni la dictadura", tal y como esta fue entendida en la república romana luego de que el cónsul Lucio Cornelio Sila usurpará el poder público. Más bien, la labor del constituyente se limitó a robustecer la figura del Ejecutivo, facultándolo con las atribuciones necesarias para que pudiera enfrentarse a las situaciones que atentaran contra la independencia política de la nación mexicana. Tal es el propósito último del artículo 29 constitucional "e interpretarlo de otra forma es contrariar con el espíritu de la Constitución”. Y aunque el pueblo mexicano ha sido oprimido durante mucho tiempo por esta ley, ese mismo pueblo ha encomendado a uno de sus hijos más ilustres, el general Porfirio Díaz Morí, el restablecimiento íntegro de la ley fundamental del país, la cual otorga protección y amparo al ciudadano Faustino Goribar que ha sido víctima de las arbitrariedades del régimen anterior. Por lo tanto, al aprobar esta resolución el Poder Judicial cumple con uno de sus más sagrados deberes el cual consiste en "guardar y hacer guarda la Constitución Federal en todo momento".

Así concluye el discurso de Ezequiel. Posteriormente, el autor añadió la sentencia dada por el pleno de la Corte el 6 de julio de I877 y las respuestas de los abogados a quienes preguntó por el alcance de las facultades extraordinarias. Por razones que desconocemos, el licenciado José María Romero Díaz fue el único que no autorizó la publicación de su respuesta. ${ }^{\text {I9 }}$

\section{Consideraciones finales}

A pesar de que Ezequiel no fue la única persona que intentó darle una mayor relevancia al movimiento tuxtepecano y mostrarlo como la mejor opción -sino es que la única- para el desarrollo político del país, 
si fue el primero en abordar la cuestión desde el punto de vista jurídico, ofreciendo una interpretación más acabada de los principios anunciados en el Plan de Tuxtepec reformado en Palo Blanco. En ese sentido, puede afirmarse que los argumentos presentados por Montes sobrepasaron las expectativas de los abogados que formaron parte del primer gabinete de Díaz y que, a lo largo de su gobierno, buscarían sucederlo en la presidencia como fue el caso de Protasio Tagle, Pedro Ogazón, Ignacio Luis Vallarta (presidente de la Suprema Corte de Justicia en aquellos momentos), Justo Benítez y Vicente Riva Palacio (Cosío, 1970).

Quizá, la mayor decepción de Montes provino del hecho de que su discurso no obtuvo el recibimiento esperado, a pesar de las copias que el mismo distribuyó entre los círculos políticos y la prensa. Esto no podría ser de otra forma pues la nueva generación lo siguió considerando como "un personaje de museo" cuya importancia radicaba en el hecho de "haber acompañado a ciertas notabilidades muertas". En contraste, sus viejos amigos que sí tuvieron la oportunidad de leer su discurso lo consideraron como "la obra maestra del distinguido jurisconsulto y notable orador Ezequiel Montes Ledesma”. Por esta razón, el abogado queretano Blas José Gutiérrez Flores Alatorre decidió dedicarle dos ejemplares de su obra titulada Apuntes sobre los fueros y tribunales militares, federales y demás vigentes en la República (Cosío, 1970; Olivera, 2019).

Finalmente, el mayor reconocimiento a su trabajo provino del general Díaz quien lo visitó en su domicilio ubicado en la calle de Santa Clara, número Io. En aquella reunión, Montes aprovechó para solicitarle al presidente constitucional de la República Mexicana un puesto de trabajo para su hijo Agustín Montes y Rebollar en la Oficina del Registro Civil. A la larga, sus relaciones políticas impulsarían la carrera parlamentaria de Agustín, quien formó parte de la IX legislatura. (Olivera, 2019). Y aunque Ezequiel murió en enero de I883, el general Díaz nunca olvidó su consejo y durante todo el tiempo que permaneció en el poder, jamás solicitó al Congreso el uso de las facultades extraordinarias, ni siquiera cuando el movimiento antirreeleccionista 
de Francisco I. Madero estalló la tarde del 20 de noviembre de i9ıo. Pero eso será tema para otro artículo.

\section{Referencias}

AHSCJN. [Archivo Histórico de la Suprema Corte de Justicia de la Nación]. (1877). Tribunal Pleno [caja 63, exp. 6044, reg. 6003]. Ciudad de México.

AHSCJN. (I877). Asuntos económicos [caja 293, exp. 3247I, reg. 3562I]. Ciudad de México.

Ávila Ortiz, R., Castellano Hernández, E., y Pilar Hernández, M. (20I5). Porfirio Díaz y el Derecho. Balance Crítico. México: Universidad Nacional Autónoma de México / Instituto de Investigaciones Jurídicas / Cámara de Diputados.

Bonilla, J. A. (1873). Apuntes biográficos del sr. Lic. D. Ezequiel Montes. México: Tipografía de José Antonio Bonilla.

Cabrera Acevedo, L. (1989). La Suprema Corte de Justicia en la República Restaurada, I867-I876. México: Suprema Corte de Justicia de la Nación.

Cabrera Acevedo, L. (1990). La Suprema Corte de Justicia a principios del porfirismo, I877-I882. México: Suprema Corte de Justicia de la Nación.

Carregha Lamadrid, L., Pérez Domínguez, M., y Ponce Alcocer, M.E. (20I7). Miradas retrospectivas al México de Porfirio Díaz. México: El Colegio de San Luis / Instituto de Investigaciones Dr. José María Luis Mora.

Cosío Villegas, D. (1970). Historia Moderna de México (vol. IV). México: Editorial Hermes.

Díaz Mori, P. (195I). Archivo del General Porfirio Díaz. Memorias y Documentos (t. IX). México: Editorial Elede. 
Dublán, M. y Lozano, J. (I882). LegsilaciónLegislación mexicana o colección completa de las disposiciones legislativas expedidas desde la Independencia de la República [t. XII y XIII]. México: Imprenta de Eduardo Dublán.

El Foro. (I877, I2 de julio). Tribunal Pleno (p. 2). Recuperado de: http://www.hndm.unam.mx/index.php/es/

El Monitor Republicano. (I876, 23 de agosto). Una contestación al "Eco" y al "Sufragio" impugnadores del discurso del Sr. Lic. Montes" (p. I). Recuperado de: http:/www.hndm.unam.mx/index.php/es/

Garner, P. (2008). Porfirio Díaz. En W. Fowler (coord.), Gobernantes mexicanos, vol. I,. (pp. 385-40I). México: Fondo de Cultura Económica.

González y González, L. (200o). El Liberalismo Triunfante. En Historia General de México. (pp. 635-705). México: El Colegio de México.

Hernández Manríquez, J. (2019). Nociones de hermenéutica e interpretación jurídica en el contexto mexicano. México: Universidad Nacional Autónoma de México / Instituto de Investigaciones Jurídicas.

Koselleck, R. (1993). Futuro Pasado. Para una semántica de los tiempos históricos. Barcelona: Editorial Paidós.

La Linterna. (I877, 26 de marzo). Manifiesto de Sebastián Lerdo de Tejada. Recuperado de: http://www.hndm.unam.mx/index.php/es/.

La Patria. (I877, I6 de marzo). Faustino Goribar. Recuperado de: http://www.hndm.unam.mx/index.php/es/).

La Patria. (I877, I6 de marzo). Premiados de Filadelfia. Recuperado de: http://www.hndm.unam.mx/index.php/es/

Moctezuma Barragán, J. (1994). José María Iglesias y la justicia electoral. México: Universidad Nacional Autónoma de México / Instituto de Investigaciones Jurídicas. 
Montes Ledesma, E. (I877). Discurso pronunciado por el Ciudadano Magistrado E. Montes en la Audiencia del día 6 de Julio de I877. México: Imprenta de Francisco Díaz de León.

Ochoa, Á. (2003). Breve Historia de Michoacán. México: El Colegio de México / Fondo de Cultura Económica.

Olivera López, L. (2019). Correspondencia particular de Ezequiel Montes Ledesma de la Biblioteca Nacional de México: 1872-I882. México: Biblioteca Nacional de México. Recuperado de: http://ezequielmontes.iib.unam.mx/index.php

Peñafiel, A. (I9II). Ciudades coloniales y capitales de la República Mexicana: historia colonial de Querétaro, desde su fundación hasta la caída del emperador Maximiliano de Habsburgo. México: Imprenta y Fototipia de la Secretaría de Fomento.

Perry, B.L. (1996). Juárez y Díaz. Continuidad y ruptura en la política mexicana. México: Universidad Autónoma Metropolitana / Editorial Era.

Pi-Suñer, A. (2008). Sebastián Lerdo de Tejada. En W. Fowler (coord.), Gobernantes mexicanos, vol. I, (pp. 339-360). México: Fondo de Cultura Económica.

Quirarte, M. (1998). Visión panorámica de la Historia de México. México: Porrúa.

Serrano Álvarez, P. (2012). Porfirio Díaz y el Porfiriato. [(Cronología I830I9I5]). México: Instituto Nacional de Estudios Históricos de las Revoluciones de México.

100 Soto, E. (coord.) (1985). Los presidentes de México ante la Nación: informes, manifiestos y documentos de I82I a I984 (t. I). México: Cámara de Diputados / LIII Legislatura. 


\section{Notas:}

${ }^{\text {I }}$ Daniel Cosío Villegas fue el primero en señalar este hecho, llegando a la conclusión de que Díaz "siempre fue alérgico a la intelectualidad".

${ }^{2}$ La correspondencia particular de Montes ha sido catalogada por el Proyecto Unitario de Reorganización del Fondo Reservado de la Biblioteca Nacional de México, del cual formé parte. Está disponible para su consulta pública en la siguiente dirección electrónica: http://ezequielmontes.iib.unam.mx/index.php

${ }^{3}$ Fue durante su administración que se logró la incorporación de estas leyes a la Carta Magna y se pudo restablecer el Senado, algo que Juárez ya había propuesto desde I867 (Pi-Suñer, 2008).

${ }^{4} \mathrm{Al}$ respecto, véase las editoriales del $\mathrm{I}^{\circ}$ de enero de $\mathrm{I} 877$, publicadas por El Monitor Republicano y El Siglo Díez y Nueve.

${ }^{5}$ Actualmente estoy realizando una biografía sobre este personaje como parte de mi tesis de licenciatura.

${ }^{6}$ Años más tarde, cuando el general Manuel González se convirtió en presidente, le devolvió el favor nombrándolo Ministro de Justicia e Instrucción Pública, cargo que ocupó hasta su muerte, ocurrida en enero de i883.

${ }^{7}$ Taxhidó (que en lengua otomí significa piedra blanca) es una cañada que forma parte de la laguna de Zimapan y está ubicada al norte del municipio de Tecozautla, entre los límites de Hidalgo y Querétaro. Sus aguas tienen fama de ser unas de las más puras del mundo y poseer propiedades curativas. En la actualidad, aún pueden observarse los restos de los baños construidos por Montes.

${ }^{8}$ Faustino Goribar nació en Saltillo, Coahuila, el I5 de febrero de I8I9. En fecha indeterminada llegó a la capital del país y ahí contrajo matrimonio con la señorita Brígida Zavala en enero de I869. Fue por esa época cuando adquirió la Hacienda de Casasano en el estado de Morelos, la cual llegó a convertirse en un próspero ingenio azucarero; tan es así que en I876 Goribar ganó un premio en la Exposición Universal de Filadelfia. Por otra parte, no existen indicios de que Goribar haya conocido a Montes previó a la solicitud de amparo y si le agradeció o no el fallo resolutivo es algo que no hemos podido averiguar (La Patria, I877, Premiados de Filadelfia).

${ }^{9}$ De acuerdo con el testimonio de Montes, el discurso en sí duró poco más de dos horas y fue pronunciado a viva voz, sin utilizar ningún soporte textual. La sentecnia de este caso pude consultarse en El Foro (I877).

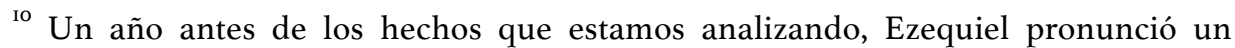
discurso similiar a favor del teniente coronel Manuel Blanco, quien había sido apresado en la cárcel de Belén bajo el cargo de conspirardor, sin que hasta ese 
momento se le hubiera demostrado su culpabilidad. Fue en esa ocasión donde Montes formuló por primera vez cuales deberían ser los límites de las atribuciones de un presidente investido con facultades extraordinarias. Sin embargo, su alegato no fue bien recibido por la prensa lerdista, la cual no dejó de criticarlo. Finalmente, Enrique Chavarri, mejor conocido como Juvenal, salió en defensa del magistrado y demostró la validez de su razonamiento (El Monitor Republicano, I876).

${ }^{\text {II }}$ Debido a una desavenencia con Ignacio Cumplido, Montes dejó de publicar sus textos en la imprenta que este persoanje dirigía. Además, es importante mencionar que el viaje que realizó Ezequiel desde la Ciudad de México no fue fácil, pues implicó una movilización de los siguientes materiales: un cajón de libros, plumas, tintero, papel, sus enseres personales, algunos viveres y los preparados médicos. Todo ello siendo transportado por la dilgencia y la recua de mulas en caminos de terracería aún controlados por bandas de "tuxtepecanos".

${ }^{\mathrm{I} 2}$ El hecho de que Montes le dedicara un ejemplar a Guillermo Prieto no es fortuito ya que este último apoyó las pretensiones presidenciales de José María Iglesias e incluso llegó a formar parte de su gabinete como Ministro de Gobernación, siendo uno de los pocos que lo acompañaron en su travesía por los Estados Unidos. Finalmente, ambos regresarían al país en octubre de $\mathrm{I} 877$ y, posterormente, Prieto publicaría su Viaje a los Estados Unidos. Esto nos demuestra que Ezequiel procuró atraerse a los partidarios de Iglesias, probándoles que el movimiento tuxtepecano era el único comprometido con la defensa integral de la Constitución.

${ }^{13}$ En su juventud, Montes fue un alumno destacado del Nacional y Más Antiguo Colegio de San Ildefonso, llegando a convertirse en catedrático de gramática latina. Posteriormente completo sus estudios en la Academia Teórico-Práctica de Jurisprudencia, donde recibió nociones de derecho romano e hispano, así como de historia patria y universal. Durante su estadía en Europa, perfeccionaría sus conocimientos en latín y antigüedad romana. Por esta razón, no es de extrañar que Ezequiel estuviera más que familiarzado con las artes del trivium, esto es, la gramática, la logica y la retórica. Por otra parte, la noción de Historia Magistra Vitae previvió desde la Antigüedad hasta la profesionalización de los estudios historicos en la segunda mitad del siglo XIX, por lo que no es extraño que el autor la siguiera utilizando como orientadora de la praxis juridica (Koselleck, I993).

$102{ }^{\mathrm{I} 4}$ En mi opinión, es en esta parte donde podemos captar más ampliamente el sentido que Montes tenía sobre la Historia como magistra vitae, pues proyecta sus esperanzas en el futuro fundamentádolas con los ejemplos del pasado y, al hacerlo, crea un "horizonte de posibilidad" que sirve para indicarle a Díaz cuál es el camino a seguir para que esto último se realice. Por otra parte, el hecho de considerar a México como "el país de lo imprevisto" proviene de su experiencia durante la Segunda Intervención Francesa (Olivera, 2019).

${ }^{15}$ De no haber sido por su enfermedad, Ezequiel hubiera tomado parte de la discusión que revisó el amparo de "Morelos", mejor conocido como de incompetencia de origen, 
en el cual tuvo una destacada participación el licenciado José María Iglesias (Cabrera, I989).

${ }^{16}$ Si bien Lincoln no recurrió al uso de las facultades extraordinairas, las cuales ni siquiera figuran en la Constitución Política de los Estados Unidos de América, si suspendió el derecho del habeas corpus e impuso la ley marcial con el fin de que las autoridades militares pudieran garantizar el orden y la paz pública en los estados pertenencientes a la Unión. Como puede imaginarse, esto provocó una ola de crítcias en la prensa y en el Congreso donde los representaes demócratas no dudaron en acusarlo de querer imponer una tiranía.

${ }^{17}$ Es significativo que Montes retome esta frase que proviene del Manifiesto del presidente de la Suprema Corte de Justicia a la Nación, el cual fue escrito por José María Iglesias para justificar sus propias aspiraciones presidenciales luego de desconocer la reelección de Sebastián Lerdo de Tejada. ¿Pretendió con ello atraerse el apoyo de Iglesias demostrándole la validez constitucional del movimiento tuxtepecano?, ¿fue un intento para que Iglesias regresara a la vida pública? Esto último es más probable ya que Ezequiel siguió en contacto con el antiguo magistrado e incluso llegó a propronerle que se incorporara al gabinete de Manuel González, algo que Iglesias nunca aceptó (Olivera, 20I9).

${ }^{18}$ Tales eran las esperanzas que Montes tenía respecto al régimen tuxtepecano. Su muerte -acaecida en I883- le impidió ver el segundo ascenso de Díaz a la presidencia y la construcción de la dictadura porfirista a partir de I888.

${ }^{19}$ Los abogados a quienes consultó fueron los siguientes: José María Mata, Mariano Yáñez, José María Romero Díaz, León Guzmán, Pedro Escudero y José María del Castillo Velasco.

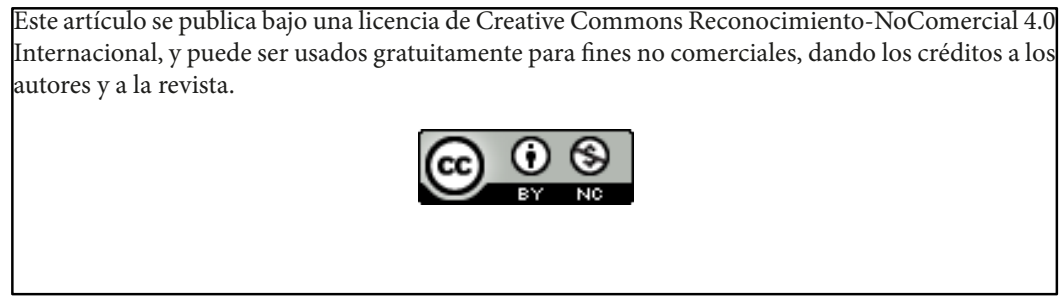

